\title{
UPAYA MENINGKATKAN MOTIVASI BELAJAR MENGOPERASIKAN APLIKASI PRESENTASI DENGAN MENERAPKAN MODEL KONTEKSTUAL SISWA KELAS 11 AP 1 SMK NEGERI 3 BANDUNG
}

\author{
THE EFFORTS TO IMPROVE THE LEARNING MOTIVATION IN OPERATING \\ PRESENTATION APPLICATION USING CONTEXTUAL MODEL AT CLASS 11 \\ VOCATIONAL SCHOOL NO. 3 BANDUNG
}

\author{
Gina Madiana \\ Guru Administrasi Perkantoran SMK Negeri 3 Bandung \\ E-mail: ginamadiana61@yahoo.com
}

\begin{abstract}
ABSTRAK
Objek penelitian adalah siswa kelas 11 AP 1, dilatarbelakangi oleh adanya kesulitan siswa dalam memahami materi Mengoperasikan Aplikasi Presentasi Kompetensi Dasar Mendeskripsikan Apliksi Presentasi di SMK Negeri 3 Bandung.Materi ini sering dianggap materi yang menyulitkan dan membosankan, khususnya di SMK, padahal kemampuan ini amat diperlukan pada pelaksanaan pekerjaan khususnnya para siswa kompetensi Administrasi Perkantoran, dimana mereka jika telah menyelesaikan studinya diharapkan harus mampu dan terampil menerapkannya dalam melaksanakan khususnya menyiapkan bahan untuk dipresentasikan. Salah satu upaya untuk meningkatkan motivasi belajar siswa dengan menggunakan modul sebagai sumber belajar siswa.

Penelitian Tindakan Kelas ini dimaksudkan untuk: (1) Mendapatkan gambaran mengenai penerapan modul sebagai sumber belajar; (2) Mengidentifikasikan kesulitan yang dihadapi siswa dalam memahami konsep Mengoperasikan Aplikasi Presentasi dengan menerapkan modul sebagai sumber belajar; (3) Mendeskripsikan perubahan siswa dalam proses pembelajaran melalui penerapan modul sebagai sumber belajar; dan (4) Metode yang digunakan adalah metode deskriptif dengan penyebaran angket, observasi dan tes hasil pembelajaran yang menjadi subjek penelitian adalah kelas 11 AP 1 di SMK Negeri 3 Bandung.Masil penelitian ini memperlihatkan bahwa pembelajaran Mengoperasikan Aplikasi Presentasi Kopetensi Dasar Mendeskripsikan Aplikasi Presentasi dengan menggunakan modul sebagai sumber belajar, setelah dilakukan tindakan melalui penelitian ini, memperlihatkan adanya peningkatan perolehan hasil belajar dan motivasi belajar siswa baik dilihat dari segi nilai secara individu ataupun nilai ratarata.
\end{abstract}

Kata kunci: model pembelajaran kontekstual

\section{ABSTRACT}

The object of the research is the 11th grader AP 1, backed by the difficulties of students in understanding the material Operating Application Presentation Basic Competence Describing Presentation Application in SMK Negeri 3 Bandung.This material is often considered difficult and tedious material, especially in vocational school, whereas this ability is very necessary in the implementation of special work of the students of Office Administration Competence, where they have completed their study if they have to be able and skillfully apply it in implementing specially prepared material to be presented. One effort to improve students'learning motivation by using the module as a learning resource for students.Classroom Action Research is intended to: (1) Getting a picture of the application of the module as a learning resource; (2) Identify difficulties faced by students in understanding the concept of Operating Presentation Application by applying the module as a learning resource; (3) Describe the changes of students in the learning process through the application of the module as a source of learning; and (4) The method used is descriptive method with the spreading of questionnaire, observation and test result of study which become research subject is class 11 AP 1 in SMK Negeri 3 Bandung.This study demonstrates that learning to Operate Presentation Application of Basic Competence Describes Presentation Application using module as learning resource, after doing the action through this research, showing the improvement of learning achievement result and student's learning motivation either in terms of individual value or average value.

Keywords :contextual learning model 


\section{PENDAHULUAN}

Fungsi Pendidikan Nasional adalah mengembangkan kemampuan dan membentuk watak serta peradaban bangsa yang bermartabat dalam rangka mencerdaskan kehidupan bangsa, bertujuan untuk mengembangkan potensi peserta didik agar menjadi manusia beriman dan bertakwa kepada Tuhan Yang Maha Esa, berakhlak mulia, sehat, berilmu, cakap, kreatif, mandiri, dan menjadi warga Negara yang demokratis dan bertanggung jawab (pasal 3 Undangundang N0. 20 Tahun 2003). Oleh sebab itu setiap pendidik dituntut untuk senantiasa mengembangkan dan mengoptimalkan kualitas peserta didik agar mampu bersaing untuk menghadapi era globalisasi sekarang ini.

Begitu pula dalam pelajaran Mengoperasikan Aplikasi Presentasi, guru Mengoperasikan Aplikasi Presentasi perlu terus menerusberupaya secara kreatif mencari ide-ide dan cara-cara barudalam pelaksanaan pembelajarannya. Apalagi mata pelajaran Mengoperasikan Aplikasi Presentasi bagian dari ilmu computer terus berkembang pada masa kini dan mendatang baik materi maupun kegunaannya. Oleh sebab itu, berbagai faktor pendukung keberhasilan proses belajar mengajar Aplikasi presentasi secara periodik harus terus dibenahi termasuk dalam upaya penyusunan kembali bahan ajar, model pembelajaran serta sarana pembelajaran yang dilakukan di sekolah khususnya di sekolah kejuruan.

Model pembelajaran konstektualisme dapat menjadi salah satu model yang dapat dikembangkan dalam pelajaran Mengoperasikan Aplikasi Presentasi. Dengan model ini akan menjadi kebiasaan guru yang bersifat otoriter menjadi motivator, mengubah proses secara yang menjenuhkan menjadi proses pembelajaran yang menyenangkan.

Model pembelajaran konstektualisme dalam pelajararan Mengoperasikan Aplikasi Presentasi dapat diwujudkan dengan menggunakan sumber belajar yang amat Jurnal Penelitian Pendidikan menarik dengan menggunakan modul dengan disajikan dengan uraian yang sistematis dan menarik.

Dengan cara tersebut akan lebih menunjukan bahawa guru dalam melaksanakan proses pembelajaran diharapkan memiliki profesionalisme yakni dalam melaksanakan tugasnya sesuai dengan tujuan yang diharapkan.

Kebiasaan menyusun bahan ajar pada saat ini belum sepenuhnya dimiliki oleh pendidik. Penulis menyadari betapa pentingnya modul sebagai sumber pembelajaran untuk menghasilkan proses pembelajaran yang lebih efektif guna membentuk prilaku dan karakter peserta didik yang kreatif, mandiri dan kompeten

Masalah dalam penelitian Tindakan Kelas (PTK) ini adalah kesulitan siswa kelas 11 Program Kopetensi Administrasi Perkantoran dalam memahmi dan memiliki keterampilan materi pelajaran Mengoperasikan Aplikasi PresentasikhususnyamateriMendeskripsikan Aplikasi Presentasi dan penerapannya.

Adapun rumusan masalah penelitian ini adalah: (1) Apakah pembelajaran Mengoperasikan Aplikasi Presentasi dengan konstektualisme menggunakan modul dapat meningkatkan prestasi belajar siswa kelas 11 AP 1 SMK Negeri 3 Bandung?; (2) Bagaimana aktivitas siswa kelas 11 AP 1 dalam pembelajaran dengan model konstruktifisme menggunakan modul?; dan (3) Sejauh manakah ketrampilan kooperatif siswa kelas 11 AP 1 dapat dimunculkan dalam pembelajaran model konstektualisme menggunakan modul?

Tujuan utama Penelitian Tindakan Kelas ini adalah untuk meningkatkan prestasi siswa kelas 11 AP 1 pada pembelajaran Mengoperasikan Aplikasi Presentasi dengan menggunakan model pembelajaran konstektualisme.

Tujuan khusus adalah mengetahui dan mengkaji: (1) Peningkatan prestasi belajar siswa dalam pembelajaran Mengoperasikan Aplikasi Presentasi dengan menggunakan 
model konstektualisme menggunakan modul; (2) Aktivitas belajar siswa dengan model pembelajaran konstektualisme; dan (3) Kemampuan kooperatif siswa dalam pembelajaran Mengoperasikan Aplikasi Presentasi dengan model pembelajaran konstektualisme.

Hasil penelitian ini diharapkan dapat digunakan untuk mengembangkan IPTEK, khususnya pada Pembelajaran Mengoperasikan Aplikasi Presentasi diperuntukan: (1) Bagi Siswa, untuk meningkatkan minat dan motivasi serta prestasi; (2) Siswa dapat meningkatan aktifitas dan semangat kooperatif dalam belajar baik secara individual juga secara kelompok; (3) Bagi pengajar dapat memperoleh gambaran tentang pembelajaran Mengoperasikan Aplikasi Presentasi yang efektif dan menyenangkan; (4) Para Pendidik dapat mengidenfivikasikan permasalahan yang timbul di kelas, sekaligus mencari pemecahan masalahnya; dan (5) Para pendidik dapat menyusun program peningkatan efektifitas pembelajaran Mengoperasikan Aplikasi Presentasi pada tahap selanjutnya.

\section{METODE PENELITIAN}

Metode penelitian yang digunakan dalam penelitian ini adalah penelitian tindakan kelas. Penelitian Tindakan kelas merupakan salah satu usaha untuk memperbaiki kualitas pendidian yang secara langsung melibatan masalah di lapangan, yaitu masalah yang terjadi di dalam proses pembelajaran Mengoperasikan Aplikasi Presentasi.indakan Kelas ini meliputi prosedur perencanaan, pelaksanaan, observasi, dan refleksi.

Tujuan dari penggunaan metode penelitian tindakan kelas ini adalah untuk memecahkan maslah-masalah praktkajian yang bersifat reflektif, yang dilakukan oleh pelaku tindakan untukik pembelajaran di suatu sekolah khususnya di kelas tertentu. Metode penelitian ini juga dilakukan untuk perbaian dan peningkatan layanan professionalpendidik dalam menangani belajar mengajar di kelas.

\section{Prosedur Penelitian}

Pelaksanaan penelitian dilakukan secara kolaborasi dengan observer yang membantu dalam pelaksanaan observasi dan refleksi selama penelitian berlangsung, sehingga secara tidak langsung kegiatan penelitian bisa terkontrol sekaligus menjaga kevalidan hasil penelitian. Jenis penelitian yang digunakan dalam penelitian ini adalah penelitian tindakan kelas, karena tindakan yang akan dilakukan diterapkan pada pembelajaran dalam kelas. Penelitian ini dimulai dari tahap identifikasi masalah mengenai pelaksanaan pembelajaran Mengoperasikan Aplikasi Presentasi dan analisis penyebab munculnya masalah. Prosedur penelitian menggunakan siklus, yang terdiri atas tahap :

1. Perencanaan

Perencanaan yang merupakan upaya untuk memperbaiki kelemahan dalam proses pembelajaran

2. Pelaksanaan tindakan yaitu melaksanakan proses pembelajaran,

3. Pengamatan/observasi untuk mengetahui kemampuan peserta didik dan untuk mengukur sikap positif dan negative peserta didik dalam kegiatan pembelajaran dan

4. Tahap Refleksi (perenungan, pemikiran, dan evaluasi) di setiap siklusnya untuk mengkaji, melihat dan mempertimbangkan hasil atau dampak dari tindakan (Kemmis dan Taggart, 1988).

\section{Teknik dan Alat Pengumpul Data}

Berdasarkan pada keempat tahapan penelitian dan pengembangan model bahan ajar yang meliputi: (1) studi pendahuluan (2) perencanaan (3) uji coba model(4) uji validasi model maka teknik yang digunakan untuk mengumpulkan data adalah: dokumentasi, obsevasi, quesioner, wawancara, dan tes unjuk kerja. 


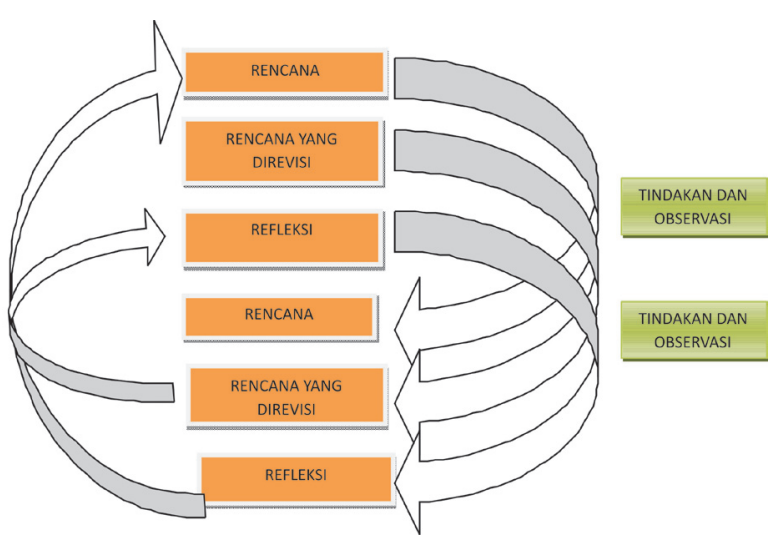

Dari gambar tersebut dapat disimpulkan bahwa dengan menerapkan perencanaan, pelaksanaan, pengamatan, dan tahap refleksi akan dapat mengatasi kesulitan yang dihadapi guru mata pelajaran Mengoperasikan Aplikasi Presentasi sehingga dapat menghasilkan hasil pembelajaran sesuai dengan tujuan belajar.

\section{HASIL PENELITIAN DAN PEMBAHASAN}

1. Hasil Studi Pendahuluan

Kondisi awal penelitian diperoleh dari peneliti yang merasakan ada proses pembelajaran yang kurang ketika mengajarkan mata pelajaran Mengoperasikan Aplikasi Presentasi kepada peserta didik, khususnya pada pembelajaran Mengoperasikan Aplikasi Presentasi. Penyajian materi pelajaran yang disampaikan pengajar secara lisan berpengaruh terhadap ketrampilan peserta didik dalam menyiapkan alat dan langkahlangkah dalam prosespengetikan naskah kantor dalam bentuk bahan presentasi.

Berdasarkan data analisis hasil asesmen diatas, maka terlihat bahwa karakteristik peserta didik. Kesulitan untuk mengurutkan langkah langkah dalam pelaksanaan pembelajaran pelaksanaan pembelajaran Mengoperasikan Aplikasi Presentasi. Kemudian karakteristik peserta didik yang kurang inisiatif dalam mempelajari sesuatu menyebabkan peserta didik membutuhkan model yang dapat memberikan inspirasi yang lebih baik.

Hasil pengamatan oleh observer yang dilihat dari tiap pertemuan proses pembelajaran yang menerapkan model pembelajaran kontekstual menggunakan modul dapat dilihat pada tabel di bawah.

\begin{tabular}{lrrr}
\hline \multicolumn{1}{c}{ Indikator Siswa } & Siklus I & \multicolumn{1}{c}{ Siklus II } & Siklus III \\
\hline Aktivitas siswa & 2 & 8 & 15 \\
\hline Perhatian & 4 & 18 & 17 \\
\hline Acuh & 27 & 7 & 1 \\
\hline Hasil Prestasi Belajar & $69.70 \%$ & $75.29 \%$ & $79.38 \%$ \\
\hline
\end{tabular}

Pembelajaran kontekstual menggunakan modul ini dapat diterapkan diKelas 11 AP 1SMK Negeri 3 Kota Bandung, sebagai salah satu alternative untuk mengatasi pembelajaran pelaksanaan pembelajaran Mengoperasikan Aplikasi Presentasi.

\section{Model Bahan Ajar}

Berikut ini model bahan ajar untuk meningkatkan keterampilan Mengoperasikan Aplikasi Presentasi di kelas 11 AP 1.

\section{A. Pembahasan Hasil Penelitian}

Penelitian ini menggunakan penelitian tindakan kelas, dengan subjek 38 orang peserta didik kelas 11 AP 1. Dan dilakukan dalam tiga siklus yaitu siklus I, siklus II dan siklus III. Sebelum penelitian, terlebih dahulu diadakan studi pendahuluan dengan berproses untuk mengetahui kondisi awal peserta didik sebelum memperoleh penerapan model pembelajaran kontekstual berbasis modul. Dari hasil studi pendahuluan, diketahui bahwa belum optimalnya proses pembelajaran Mengoperasikan Aplikasi Presentasi yang menggunakan metode ceramah dan demonstrasi yang diterapkan pada peserta didik, dalam mengoptimalkan potensi peserta didik. Kemudian dengan adanya satu orangpendidik dalam satu kelas ketika mengajarkan mata pelajaran 


\begin{tabular}{lrr}
\hline Mengoperasikan Aplikasi & Presentasi, \\
menyebabkanpendidik harus & bertindak \\
sebagai model yang mendemonstrasikan \\
kemampuan Mengoperasikan & Aplikasi \\
Presentasi yang dipelajari dan & sebagai \\
orang yang mengarahkan agar & peserta \\
didik memperhatikanpendidik & ketika \\
mendemonstrasikan pengetikan. &
\end{tabular}

Ketika pendidik mendemonstrasikan, peserta didik cenderung tidak konsentrasi, kurang antusias dan kurang aktif serta kurang mandiri dalam proses pembelajaran. Kemudian selain proses pembelajaran yang kurang efektif, keterbatasan keterampilan peserta didik berpengaruh terhadap kemampuan peserta didik dalam menerapkan, alat, dan langkah-langkah dalam prosespengetikan naskah kantor sehingga nilai peserta didik masih berada di bawah KKM. Hasil pengamatan yang dilakukan pada siklus I, II dan III menunjukkan keberhasilan penerapan model pembelajaran kontekstual menggunakan modul. Keberhasilan ini dapat dilihat dalam proses pembelajaran dan kenaikan nilai peserta didik dalam pelaksanaan pembelajaran Mengoperasikan Aplikasi Presentasi yang berada diatas KKM, sehingga peserta didik dapat dikatakan tuntas dalam belajar dan mandiri dalam pelaksanaan pembelajaran Mengoperasikan Aplikasi Presentasi.

Bagian ini menguraikan tentang pembahasan hasil penelitian dari tinjauan teori yakni: (1) hakekat pengembangan model (2) karakteristik model bahan ajar (3) hasil implementasi bahan ajar yang dikembangkan, dan (4) faktor-faktor pendukung dan penghambat implementasi model bahan ajar yang dikembangkan dalam penelitian ini.

\section{SIKLUS I SIKLUS II DAN SIKLUS III}

Skala Penilaian

$0-19=$ Hanya mengetik angka tanpa mendesign power point

$20-39=$ Mendesign power point baru
$40-59=$ Mendesign power point sebagian dan belum disempurnakan

$60-79=$ Mendesign belum sempurna

$80-99=$ Hasil design sempurna dan memuaskan

$100=$ Istimewa

(Hasil penilaian dapat diperhatikan dari daftar nilai siklus I, II, dan III yang telah penulis paparkan )

\section{SIMPULAN}

Berdasarkan hasil interpretasi dan pembahasan temuan penelitian dan pengembangan model bahan ajar maka dapat ditarik kesimpulan sebagai berikut

1. Penelitian tindakan kelas tentang penerapan model pembelajaran kontekstual menggunakan modul untuk meningkatkan kemampuanpelaksanaan pembelajaran Mengoperasikan Aplikasi Presentasipeserta didikKelas 11 AP 1SMK 3 telah dilaksanakan dalam 3 siklus kegiatan dengan menghasilkan kesimpulan sebagai berikut. Penerapan model pembelajaran kontekstual menggunakan modul dapat meningkatkan kemampuan pelaksanaan pembelajaran Mengoperasikan Aplikasi Presentasi peserta didik Kelas 11 AP 1SMK 3 Bandung. Keberhasilan penerapan model pembelajaran kontekstual menggunakan modul sebagai upaya untuk meningkatkan kemampuan pelaksanaan pembelajaran Mengoperasikan Aplikasi Presentasi peserta didik Kelas 11 AP 1 ditunjukkan dengan adanya perubahan dalam proses pembelajaran. Proses pembelajaran pelaksanaan pembelajaran Mengoperasikan Aplikasi Presentasi pada saat observer persentase proses pembelajarannya sebesar $38 \%$ yang termasuk ke dalam kategori pembelajaran tidak baik. Namun setelah diterapkan model pembelajaran kontekstual menggunakan modul, persentase proses pembelajaran terus meningkat, hingga 
pada akhir pertemuan ke 6 (siklus III) persentase proses pembelajaran menjadi 93\% yang termasuk kedalam kategori pembelajaran sangat baik. Dalam proses pembelajaran, kemampuan guru dalam membuka pelajaran, proses pembelajaran, sikappendidik, penguasaan materi, penggunaan modulpelaksanaan pembelajaran Mengoperasikan Aplikasi Presentasi dalam proses pembelajaran, evaluasi dan menutup pembelajaran menjadi lebih baik. Kemudian peserta didik menjadi lebih aktif dalam proses pembelajaran yang ditandai dengan meningkatnya perhatian, konsentrasi, keaktifan, motivasi, keantusiasan, keberanian dan pemahaman peserta didik terhadap kebermaknaan hasil pembelajaran untuk diterapkan dalam kehidupan seharihari.

2. Keberhasilan pelaksanaan tindakan dalam penelitian juga dibuktikan dari hasil belajar peserta didik. Kemampuanpelaksanaan pembelajaran
Mengoperasikan Aplikasi Presentasi apabila pada saat asesmen rata-rata hanya mendapatkan nilai 69,76 dan berada dibawah KKM. Namun setelah dilaksanakan proses pembelajaran yang menerapkan model pembelajaran kontekstual menggunakan modul, nilai peserta didik dalam pelaksanaan pembelajaran Mengoperasikan Aplikasi Presentasi terus meningkat hingga pada pertemuan ke-5 dan ke-6 pada siklus III, nilai rata-rata peserta didik menjadi 79,38 yang menunjukkan bahwa nilai peserta didik sudah berada diatas KKM $(75,00)$. Hal ini menunjukkan bahwa semua peserta didik sudah tuntas dalam belajar dan dapat mandiri dalam pelaksanaan pembelajaran Mengoperasikan Aplikasi Presentasi.

3. Efektifitas Implementasi yang dikembangkan mampu meningkatkan keterampilan Mengoperasikan Aplikasi Presentasi.

\section{DAFTAR RUJUKAN}

Aziz. 2009. Penggunaan Multimedia Berbasis Komputer Sebagai Upaya Meningkatkan Motivasi Belajar PAI SiswaKelas 11 AP 1 di SMPN 2 Temon Kulon Progo. Yogyakarta : tidak diterbitkanAstati. 2010. Mengoperasikan Aplikasi Presentasi. Bandung : CV Catur Karya Mandiri.Binham, R. 2013. Pembelajaran Menggunakan modul. [online]. Tersedia : http://cafemotivasi.com/pembelajaranberbasis-multimedia/

Jumadi. 2003. Pembelajaran Konstektual dan Implikasinya [online]. Tersedia: https://www.google.co.id/url?sa=t $\& \mathrm{rct}=\mathrm{j} \& \mathrm{q}=\& \mathrm{esrc}=\mathrm{s} \&$ source $=$ web $\& \mathrm{~cd}=5 \& \mathrm{cad}=\mathrm{rja} \&$ uact $=8 \& \mathrm{ved}=0 \mathrm{CEIQFjAE} \& u \mathrm{rl}=\mathrm{http} \% 3 \mathrm{~A} \% 2 \mathrm{~F} \% 2$ Fstaff.uny.ac.id $\% 2$ Fsystem $\% 2$ Ffiles\%2Fpengabdian $\% 2$ Fjumadi-mpddr\%2Fpembelajarankontekstual. pdf\&ei=pjiRU5f6GsnykQW6poHgCw\&usg=AFQjCNE7rx1S2LYRCb1eszoTvHI6CwSO7g

Suyitno, I. 2011. Karya Tulis Ilmiah (KTI). Bandung : PT Refika Aditama Wahyudin. 2010. Keefektifan Pembelajaran Berbantuan MultimediaMenggunakan Metode Inkuiri Terbimbing Untuk Meningkatkan Monat DanPemahaman Siswa. Semarang : tidak diterbitkan Widya, M. . Mengoperasikan Aplikasi Presentasi Bagi Anak Berkebutuhan Khusus. Bandung : tidak diterbitkan. 